\title{
SYMPOSIUM ON PREMEDICAL EDUCATION
}

Alpha Epsilon Delta, national honorary premedical fraternity, sponsored a symposium on Premedical Education at the Cleveland meeting of the Association for the Advancement of Science in September, 1944. More than seventy teachers and administrators from various colleges throughout the country attended. Dr. H. E. Setterfield, national president of Alpha Epsilon Delta, opened the Symposium and Dr. Victor Johnson, secretary of the Council on Medical Education and Hospitals of the American Medical Association, presented a paper on the "Objectives in Premedical Education" from the medical point of view. Dr. C. I. Reed of the department of physiology at the University of Illinois was to have presented a paper summarizing some opinions on premedical training as determined among the faculty and students of the five medical colleges in Chicago. Unfortunately, Dr. Reed was unavoidably absent.

A spirited discussion followed the formal remarks and showed the realization of the many important problems involved in premedical training. Plans for further investigation of these problems were proposed by Dr. Setterfield. Among these is the publication of the papers presented on the Symposium in the November issue of The Scalpel of Alpha Epsilon Delta which will be distributed to a large number of teachers and administrators along with a list of the more important questions for discussion brought out at the Symposium. The remarks and suggestions submitted will be published in pamphlet form and circulated among premedical teachers and others interested.

Copies of these publications may be had upon request to Dr. Maurice L. Moore, Secretary of Alpha Epsilon Delta, 3853 Lakewood, Detroit 15, Michigan. 